\title{
ROLE OF OXIDATIVE STRESS IN TYPE 2 DIABETES MELLITUS
}

\author{
Sandhya Menon ${ }^{1}$, Rajalekshmi $G^{2}$
}

${ }^{1}$ Assistant Professor, Department of Physiology, Government Medical College, Thrissur.

${ }^{2}$ Professor, Department of Physiology, Government Medical College, Idukki.

\section{ABSTRACT}

\section{BACKGROUND}

Diabetes mellitus is a state of increased free radical activity and increased oxidative stress plays a major role in the development of diabetic complications. The present study was conducted to find the role of oxidative stress in type 2 Diabetes Mellitus without complications.

\section{MATERIALS AND METHODS}

The descriptive comparative study group of 150 subjects was divided into 3 groups based on glycosylated haemoglobin values, which included type 2 diabetic patients with poor metabolic control, good metabolic control and normal age matched controls. Measured parameters were serum malondialdehyde level as an indicator of lipid peroxidation, glycosylated haemoglobin, lipid parameters like triglycerides and High Density Lipoprotein (HDL). Mean differences between the groups were analysed using ANOVA (Analysis Of Variance). Correlation coefficient was calculated to find out whether there was any significant association between two variables.

\section{RESULTS}

There was significant elevation of serum MDA and Triglycerides in type 2 diabetic patients with poor metabolic control when compared to patients with good metabolic control. Highly significant positive correlation was obtained between serum malondialdehyde and glycosylated haemoglobin, malondialdehyde and triglyceride. Negative correlation was found between Malondialdehyde and HDL cholesterol.

\section{CONCLUSION}

Early detection of the imbalance between oxidant and antioxidant equilibrium can prevent the risk of developing serious complications of diabetes mellitus by supplementation of antioxidant vitamins along with anti-diabetic agents.

\section{KEYWORDS}

Malondialdehyde, Lipid Peroxidation, Oxidative Stress.

HOW TO CITE THIS ARTICLE: Menon S, Rajalekshmi G. Role of oxidative stress in type 2 diabetes mellitus. J. Evolution Med. Dent. Sci. 2017;6(88):6127-6131, DOI: 10.14260/jemds/2017/1331

BACKGROUND
India with its dubious distinction of being called "The Diabetic Capital of World" is presently estimated to have over 40 million individuals affected by this deadly disease. Diabetes mellitus is a state of increased free radical activity and increased oxidative stress plays a major role in the development of diabetic complications. A currently favoured hypothesis is that oxidative stress through a single unifying mechanism of superoxide production is the common pathogenic factor underlying the development of insulin resistance, $\beta$-cell dysfunction in type 2 Diabetes mellitus ${ }^{1}$ and progression of long-term diabetic complications.

Cells continuously produce free radicals and reactive oxygen species as part of metabolic process. Free radicals derived from molecular oxygen are highly reactive metabolites and are called reactive oxygen species. In the body, reactive oxygen species cause various types of damage like lipid peroxidation and cellular damage.

'Financial or Other Competing Interest': None.

Submission 14-08-2017, Peer Review 24-10-2017,

Acceptance 30-10-2017, Published 06-11-2017.

Corresponding Author:

Dr. Rajalekshmi $G$,

Professor,

Department of Physiology,

Government Medical College,

Idukki.

E-mail: vinayraji@gmail.com

DOI: $10.14260 /$ jemds $/ 2017 / 1331$

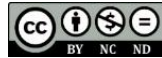

Antioxidants are enzymes or compounds that scavenge or reduce free radicals. Normally, a balance exists between concentration of reactive oxygen species and antioxidant scavenging system. Disruption of delicate balance between pro-oxidants and antioxidants results in oxidative stress. Diabetes mellitus is a state of increased oxidative stress based on increased peroxidation and decreased antioxidant status. MDA is one of the most frequently used biomarkers that provide an indicator of the overall lipid peroxidation level and oxidative stress.

\section{MATERIALS AND METHODS}

The descriptive comparative study, which was approved by Institutional Ethics Committee was conducted for a period of 6 months in patients attending diabetic clinic, Medical College, Calicut.

\section{Selection of Subjects}

3 study groups were selected. They were type II diabetic patients with poor metabolic control, type II diabetic patients with good metabolic control and normal age matched control. Based on glycosylated haemoglobin values, patients were divided into two groups. Those patients with $\mathrm{HbA}_{1 \mathrm{c}}$ values > 6.5 were assigned as poor metabolic control and those patients with $\mathrm{HbA}_{1 \mathrm{c}}$ values $<6.5$ were assigned as good metabolic control. The study parameters assayed in patients with diabetes were compared with normal age matched controls. There were equal distribution of males and females in all the study groups. 


\section{Study Design}

Descriptive comparative study.

\section{Inclusion Criteria}

All type II diabetic patients were of age group above 30 years. Normal age and sex matched subjects serve as control.

\section{Exclusion Criteria}

Patients with history of smoking, alcohol consumption, acute infections and inflammatory diseases, hepatic or renal disease, coronary heart disease, macrovascular and microangiopathic complications in diabetes were excluded from the study.

\section{Sample Size}

150 subjects with 50 subjects in each group. Formula for calculating sample size as per ANOVA.

$\mathrm{n}=\lambda / \Delta$ where $\lambda$ is calculated from non-central chi-square distribution table for power $\beta=80 \%$ and

$\Delta=\underline{1} \Sigma\left(\mu_{1}-\bar{\mu}\right)^{2}$

$\sigma^{2}$.

$\sigma^{2}=\underline{\text { SSE }}$ where SSE $=$ error sum of square calculated from ANOVA table $\mathrm{k}(\mathrm{n}-1)$

$\left(\mu_{1}-\bar{\mu}\right)^{2}=$ pair wise comparison of each group

\section{Estimation of Serum Malondialdehyde}

Malondialdehyde was measured in serum by using the thiobarbituric acid test based on Valipasha and Sadasivadu's ${ }^{2}$ procedure; $1 \mathrm{~mL}$ of serum was added to $1 \mathrm{~mL}$ of $40 \%$ trichloroacetic acid followed by addition of $2 \mathrm{~mL}$ of $0.67 \%$ thiobarbituric acid. The mixture was kept for 10 minutes in a boiling water bath and cooled immediately in ice cold water bath. The mixture was centrifuged at $6000 \mathrm{rpm}$ for 15 mins. The absorbance of supernatant was read against distilled water blank at $530 \mathrm{~nm}$.

\section{Estimation of Glycosylated Haemoglobin}

Estimation of glycosylated haemoglobin was done using glycosylated haemoglobin kit by Ion-Exchange resin method. This method was described by Franklin Bunn. ${ }^{3}$ Haemolysate is prepared by adding $50 \mu \mathrm{L}$ of whole blood to $250 \mu \mathrm{L}$ lysing reagent followed by incubation for 5 minutes to allow complete lysis of RBC $1 \mathrm{~mL}$ of haemolysate then added to IonExchange resin tube and mixed on a vortex mixer continuously for 5 minutes. The resin was allowed to settle and the resin separator was pushed down in the tube until the resin was firmly packed. The supernatant was poured directly into a cuvette and its absorbance was measured against distilled water at $415 \mathrm{~nm}(405-420 \mathrm{~nm})$.

\section{Estimation of Triglycerides: GPO Trinder Method ${ }^{4}$}

To $1 \mathrm{~mL}$ cholesterol reagent add $10 \mu \mathrm{L}$ sample. Mix well and incubate at $37^{\circ} \mathrm{C}$ for 10 minutes. Record absorbance at $505 \mathrm{~nm}$ (in autoanalyser).

\section{Estimation of HDL Cholesterol- Phosphotungstic Acid} Method

Chylomicrons, LDL and VLDL are precipitated from serum by phosphotungstic acid. The HDL Cholesterol remains unaffected in the supernatant and is estimated by adding 50 $\mu \mathrm{L}$ sample to $1 \mathrm{~mL}$ cholesterol reagent. ${ }^{5}$

\section{RESULTS}

Data were analysed using Statistical Package for Social Sciences (SPSS) version 14. Results were expressed as mean \pm SD. Mean difference between the groups were analysed using ANOVA (Analysis Of Variance). The p value of $<0.05$ was taken as the level of significance. In order to find out whether there is a significant association or not between two variables, coefficient of correlation was calculated. The correlation coefficient used to denote association between two continuously measured variables is the Pearson's correlation coefficient. Correlation co-efficient ' $r$ ' tends to lie between +1.0 and -1.0 . If $r$ is near +1 , it indicates a strong positive association between $\mathrm{X}$ and $\mathrm{Y}$, that is when one variable increases the other variable also increases. A value near -1.0 indicates a strong negative association, that is when one variable increases other decreases.

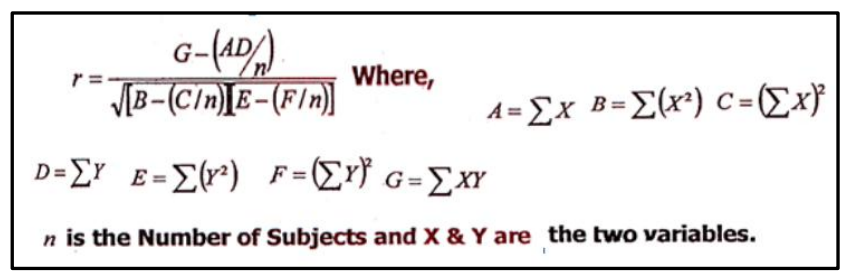

\begin{tabular}{|c|c|c|c|c|}
\hline & \multicolumn{4}{|c|}{ MDA (nmol/dL) } \\
\hline \multirow{4}{*}{$\begin{array}{c}\text { MEAN } \\
\pm \\
\text { SD }\end{array}$} & $\begin{array}{c}\text { Poor } \\
\text { Metabolic } \\
\text { Control }\end{array}$ & \begin{tabular}{|c|} 
Good \\
Metabolic \\
Control \\
\end{tabular} & Normal & $P$ value \\
\hline & $\begin{array}{c}178.9 \pm \\
34.82 \\
\end{array}$ & - & $\begin{array}{l}81.2 \pm \\
15.55 \\
\end{array}$ & $\begin{array}{c}.000 \\
\text { ( significant) }\end{array}$ \\
\hline & - & $\begin{array}{c}97.70 \pm \\
19.28\end{array}$ & $\begin{array}{l}81.2 \pm \\
15.55\end{array}$ & $\begin{array}{c}.06 \\
\text { (not } \\
\text { significant) }\end{array}$ \\
\hline & $\begin{array}{c}178.9 \pm \\
34.82\end{array}$ & $\begin{array}{c}97.70 \pm \\
19.28\end{array}$ & - & $\begin{array}{c}.001 \\
\text { (significant) }\end{array}$ \\
\hline
\end{tabular}

Table 1. Comparison of Serum MDA Values in Diabetics (Poor and Good Metabolic Control) with Control Group

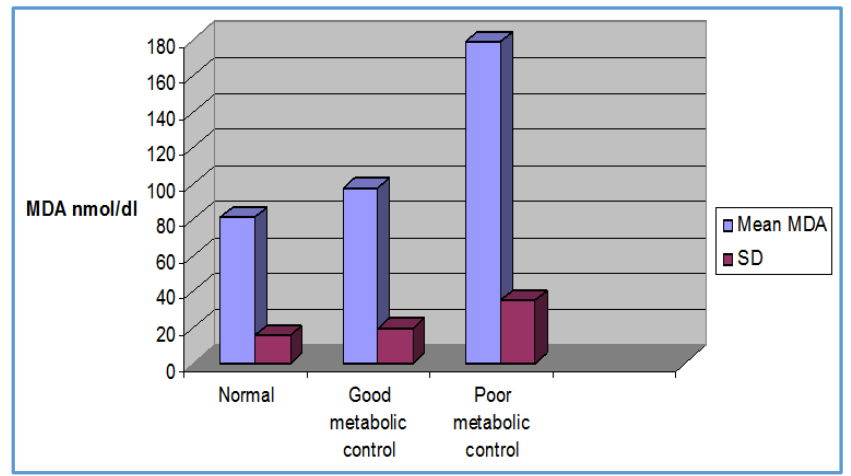

Figure 1. Significant Elevation of Serum MDA in Type II Diabetic Patients with Poor Metabolic Control when compared to Patients with Good Metabolic Control and Normal Controls 


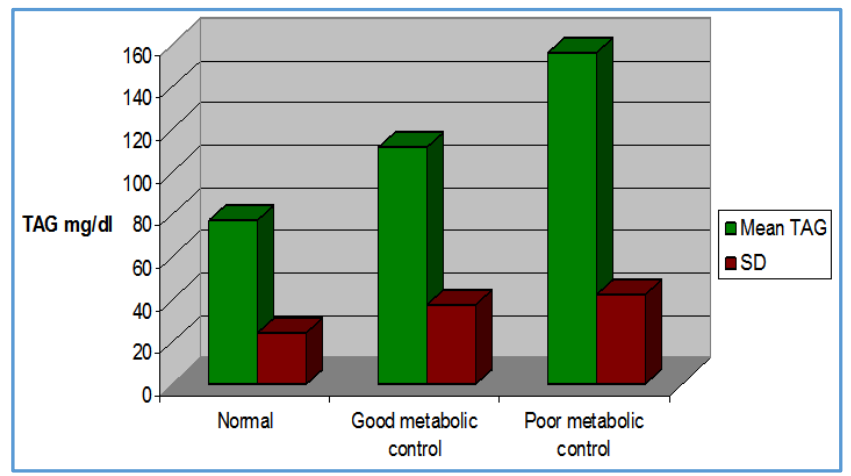

Figure 2. There was Significant Elevation of Triglycerides in Diabetics when compared to Normal

\begin{tabular}{|c|c|c|c|c|}
\hline \multirow{4}{*}{$\begin{array}{c}\text { MEAN } \\
\pm \text { SD }\end{array}$} & $\begin{array}{l}\text { Poor } \\
\text { Metabolic } \\
\text { Control }\end{array}$ & $\begin{array}{l}\text { TAG mg/dL } \\
\text { Good } \\
\text { Metabolic } \\
\text { Control }\end{array}$ & Normal & $P$ value \\
\hline & $\begin{array}{c}156.14 \pm \\
42.68\end{array}$ & - & $\begin{array}{c}77.46 \pm \\
24.57\end{array}$ & $\begin{array}{c}.000 \\
\text { (significant) }\end{array}$ \\
\hline & - & $\begin{array}{c}111.62 \pm \\
37.97\end{array}$ & $\begin{array}{c}77.46 \pm \\
24.57\end{array}$ & $\begin{array}{c}.000 \\
\text { (significant) }\end{array}$ \\
\hline & $\begin{array}{c}156.14 \pm \\
42.68\end{array}$ & $\begin{array}{c}111.62 \pm \\
37.97\end{array}$ & - & $\begin{array}{c}.000 \\
\text { (significant) }\end{array}$ \\
\hline \multirow{4}{*}{$\begin{array}{c}\text { MEAN } \\
\pm \text { SD }\end{array}$} & $\begin{array}{l}\text { Poor } \\
\text { Metabolic } \\
\text { Control }\end{array}$ & \begin{tabular}{|l|} 
HDL $\mathrm{mg} / \mathrm{dL}$ \\
Good \\
Metabolic \\
Control \\
\end{tabular} & Normal & $P$ value \\
\hline & $\begin{array}{c}44.02 \pm \\
13.10\end{array}$ & - & $\begin{array}{c}69.42 \pm \\
11.88\end{array}$ & $\begin{array}{c}.000 \\
\text { (significant) }\end{array}$ \\
\hline & - & $\begin{array}{c}59.54 \pm \\
12.60\end{array}$ & $\begin{array}{c}69.42 \pm \\
11.88\end{array}$ & $\begin{array}{c}.001 \\
\text { (significant) }\end{array}$ \\
\hline & $\begin{array}{c}44.02 \pm \\
13.10\end{array}$ & $\begin{array}{c}59.54 \pm \\
12.60\end{array}$ & - & $\begin{array}{c}.000 \\
\text { (significant) }\end{array}$ \\
\hline \multicolumn{5}{|c|}{$\begin{array}{c}\text { Table 2. Comparison of Triglyceride (TAG) and HDL } \\
\text { Values in Diabetics (Poor and Good Metabolic Control) } \\
\text { with Control Group }\end{array}$} \\
\hline
\end{tabular}

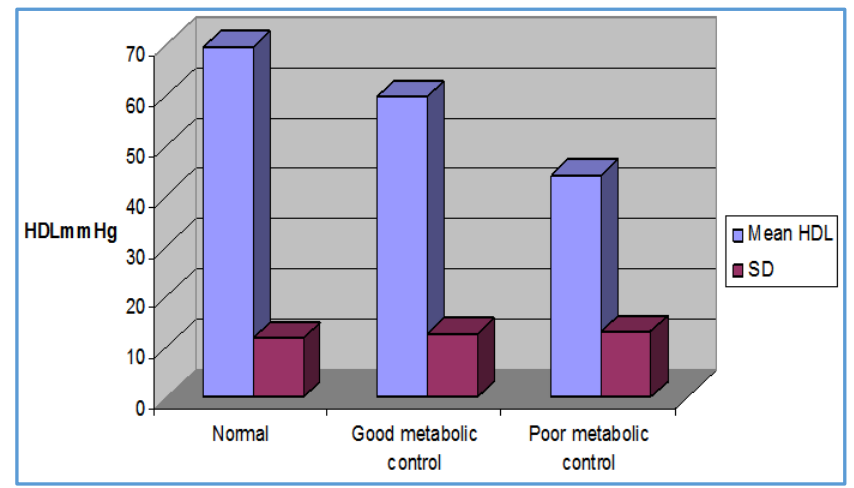

Figure 3. There was Significant Elevation of Mean HDL Values in Controls when compared to Diabetics both Poor and Good Control

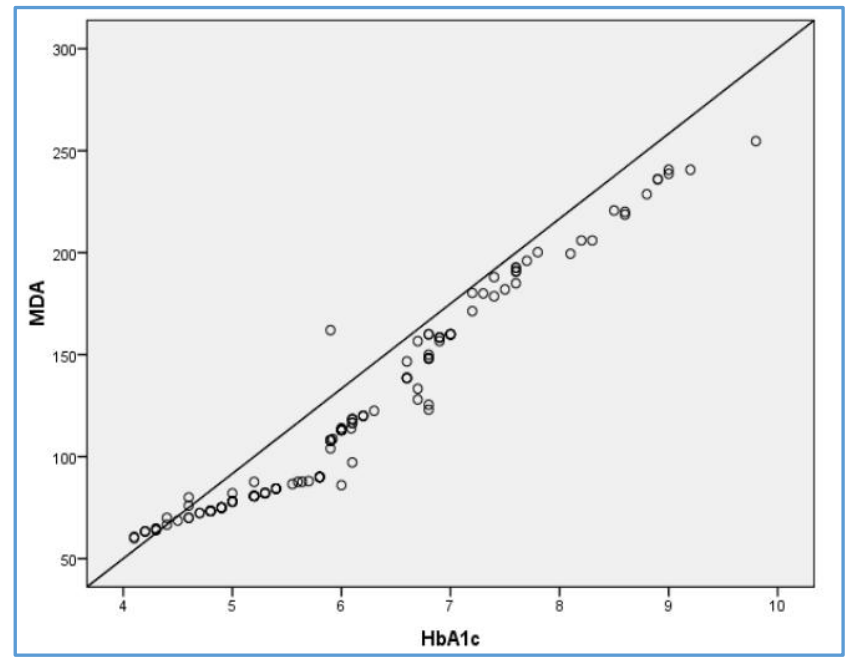

Figure 4. Scatterplot showing the Correlation between Malondialdehyde and Glycosylated Haemoglobin Values in Cases. Positive correlation. Correlation coefficient, $r=0.9, p$ value: 0.00 Highly Significant

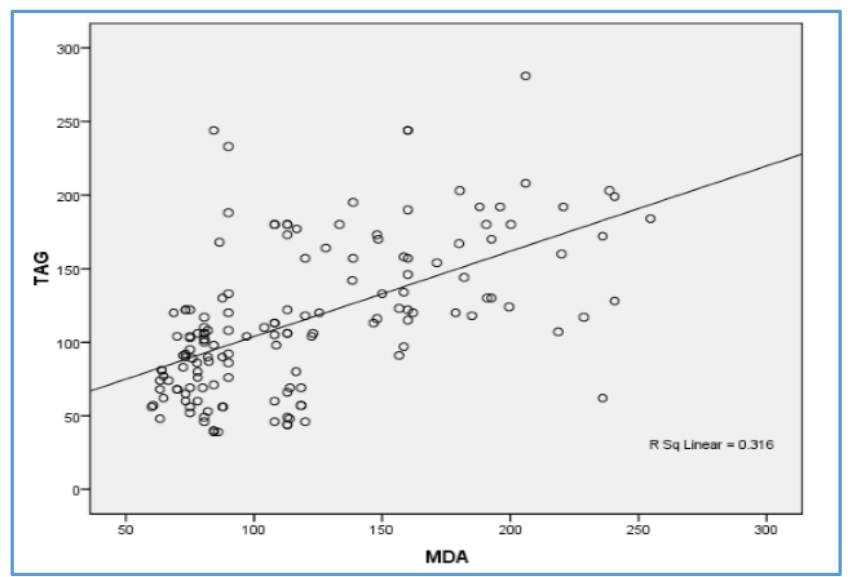

Figure 5. Scatter Plot showing the Correlation between Malondialdehyde and Triglyceride values in Cases. Positive correlation. Correlation coefficient $r=0.56, p$ value: 0.00 Highly Significant

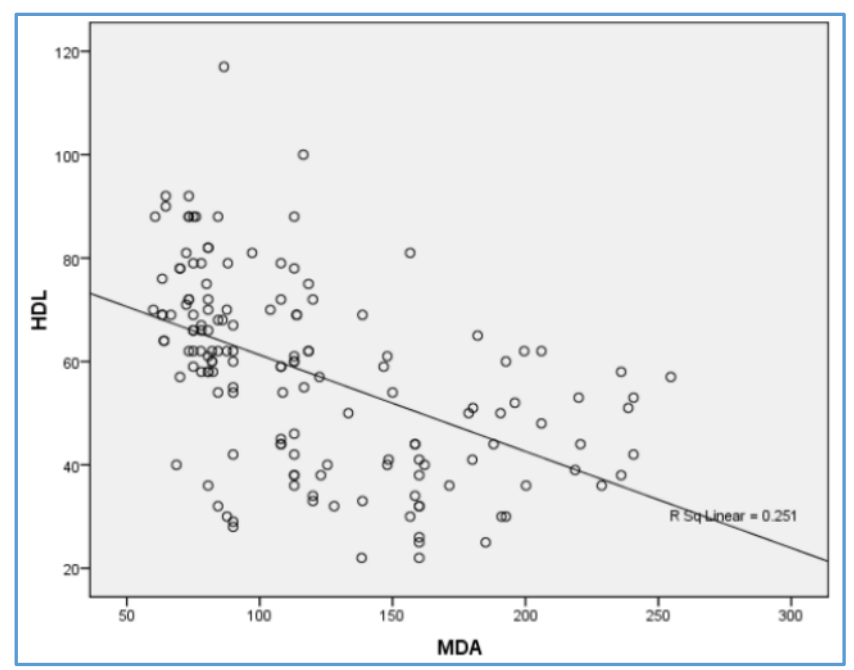

Figure 6. Scatter Plot showing the Correlation between Malondialdehyde and HDL Cholesterol values in Cases. Negative correlation. Correlation coefficient $r=-0.5$, $p$ value: 0.00 Highly Significant 


\section{DISCUSSION}

In the present study, the mean levels of serum malondialdehyde was significantly higher in diabetic patients with poor metabolic control when compared to patients with good metabolic control and normal controls (Table 1, Figure 1). There was no significant difference in mean serum MDA levels when diabetic patients with good metabolic control were compared to normal controls. The level of lipid peroxide was expressed in terms of malondialdehyde.

The increase in lipid peroxidation as reflected by a significant increase in plasma levels of MDA in diabetes are in accordance with the findings observed by Griesmacher et al. ${ }^{6}$ Prolonged hyperglycemia induces overproduction of free radicals in diabetes like superoxide, which causes lipid peroxidation and impairment of oxidant-antioxidant equilibrium.

\section{Elevated Level of Lipid Peroxide in Diabetes Mellitus may be due to ${ }^{7}$}

1. Increased glycation of proteins in diabetes mellitus, which itself act as a source of free radical.

2. Imbalance between the production and scavenging of free radicals due to deficiency of antioxidants. This will inhibit the activity of superoxide dismutase enzyme leading to the accumulation of superoxide radical, which causes maximum lipid peroxidation and tissue damage in diabetes.

3. Mitochondrial and microsomal membrane contains large amounts of polyunsaturated fatty acids with 2, 4, 5, 6 double bonds. Due to the presence of 3 or more double bonds, they are likely to be more sensitive for attack by free radicals resulting in high lipid peroxidation.

Correlation analysis revealed a significant positive correlation between glycosylated haemoglobin and serum MDA (Figure 4). Noberasco et $\mathrm{al}^{8}$ also obtained a similar positive relation. The rise in serum MDA level with rise in glycosylated haemoglobin level indicates that accumulation of serum glycosylation products has predictive value over the enhanced rate of lipid peroxidation observed in diabetic individual. Increased oxidative stress is correlating to poor metabolic control and to the development of late complications of diabetes.

A positive correlation was obtained between serum MDA and triglycerides (Figure 5). A negative correlation was obtained between serum MDA and HDL (Figure 6), both of which were found to be statistically significant. Similar results were observed by Griesmacher et al. ${ }^{6}$ Nacitarhan et $\mathrm{al}^{9}$ reported that hyperlipidemia is one of the causative factors for increased production of free radicals and lipid peroxides.

Free radicals are formed disproportionately in diabetes by glucose auto-oxidation, non-enzymatic glycation of proteins and the subsequent oxidative degradation of glycated proteins. ${ }^{1}$ The oxidative stress may be amplified by a continuing cycle of metabolic stress, tissue damage and cell death leading to increased free radical production and compromised free radical inhibitory and scavenger systems, which further exacerbate the oxidative stress. ${ }^{10}$ Since oxidative stress appears at early stages of the disease before the onset of complications, it would be the cause rather than the consequence of complications.
Improvement of glycemic control appears to be a beneficial factor to control oxidative stress. Supplementations with antioxidants play an important role in controlling oxidative stress and mitigating long-term complications in patients with diabetes.

\section{CONCLUSION}

1. The increased serum malondialdehyde levels in diabetic patients with poor metabolic control depicted the enhanced level of oxidative stress in these patients. It can be suggested that enhanced lipid peroxidation contributed to increased formation of free radicals.

2. Hyperlipidemia and hyperglycemia exacerbates oxidative stress.

3. Relation exists between hyperglycemia and oxidative stress, which could be used as prognostic marker for course evaluation of diabetes.

The results suggest that oxidative stress may appear early in type 2 diabetes mellitus patients before the development of secondary complications.

It is concluded that good metabolic control of hyperglycemia will prevent alteration in peroxidation and lipid metabolism, which may help in good prognosis and preventing manifestations of vascular and typical secondary complications in diabetes mellitus. The study paves the way for further research into the pathophysiology of oxidative stress and the role of antioxidant therapy leading to appropriately designed clinical trials in which the promise of antioxidant therapy will be realised.

\section{REFERENCES}

[1] Evans JL, Goldfine ID, Maddux BA, et al. Oxidative stress and stress-activated signaling pathways: a unifying hypothesis of type 2 diabetes. Endo Rev 2002;23(5):599-622.

[2] Pasha KV, Sadasivadu B. Intracellular content of thiol compounds, thiobarbituric acid reactive substances and gamma-glutamyl transpeptidase in rat brain during anoxia. Neuroscience Letter 1984;46(2):20914.

[3] Bunn HF. Evaluation of glycosylated hemoglobin diabetic patients. Diabetes 1981;30(7):613-7.

[4] Trinder P. Determination of glucose in blood using glucose oxidase with an alternative oxygen acceptor. Ann Clin Biochem 1969;6:24-7.

[5] Burstein M, Scholnick HR, Morfin R. Rapid method for the isolation of lipoproteins from human serum by precipitation with polyanions. J Lipid Res 1970;11(6):583-95.

[6] Griesmacher A, Kindhauser M, Andert SE, et al. Enhanced serum levels of thiobarbituric-acid-reactive substances in diabetes mellitus. American Journal of Medicine 1995;98(5):469-75.

[7] Suryawanshi NP, Bhutey AK, Nagdeote AN, et al. Study of lipid peroxide and lipid profile in diabetes mellitus. Indian Journal of Clinical Biochemistry 2006;21(1):126-30.

[8] Noberasco G, Odetti P, Boeri D, et al. Malondialdehyde (MDA) level in diabetic patients. Relation with blood glucose and glycosylated hemoglobin. Biomed Pharmacother 1991;45(4-5):193-6. 
[9] Nacitarhan S, Ozben T, Tuncer N. Serum and urine malondialdehyde levels in NIDDM patients with and without hyperlipidemia. Free Radical Biol Med 1995;19(6):893-6.
[10] Ceriello A. Oxidative stress and glycemic regulation. Metabolism 2000;49(2 Suppl 1):27-9. 